\title{
Evaluating pre and post COVID 19 learning: An empirical study of learners' perception in higher education
}

\author{
Anamika Sharma ${ }^{1} \cdot$ Irum Alvi ${ }^{2}$
}

Received: 29 January 2021 / Accepted: 22 March 2021 / Published online: 26 April 2021

(C) The Author(s), under exclusive licence to Springer Science+Business Media, LLC, part of Springer Nature 2021

\begin{abstract}
The COVID-19 pandemic has struck education system around the globe. The pandemic initiated an immediate and complete lockdown of all the educational institutions, to keep social distancing. According to healthcare professionals, lockdown and social distancing could help to flatten the infection curve and reduce total fatalities from the COVID-19 pandemic. It has affected more than $90 \%$ of the world's learners, as the regular learning approaches are not appropriate in this out of the ordinary times and online learning seems to have become a critical salvation for learning, the educational institutions attempt to minimize the community spread of the disease. All the people participating in the education system accepted that teaching and learning methods need to be altered in the period of COVID-19 as the situation led to forced adaptation of e-learning methods. This paper investigates and evaluates the learners' perception in a higher education institution of India and compares the difference in the perception of the same students in Pre and Post COVID 19 period, using the Statistical Package for Social Sciences program (SPSS) version 23.0 and JASP 0.14.1 software applications for descriptive and analytical statistics i.e. medium, minimum, maximum, paired t-test and correlation. The result of this papers confirmed that there exists a statistically significant difference in the students' perception towards the Pre-Pandemic and Post-Pandemic learning methods, which indicates that students have a higher perception of the Pre-Pandemic learning blended learning, than that of the Post Pandemic learning web-assisted learning.
\end{abstract}

Keywords Higher education · Learners' perception · Pre and post-pandemic learning

Anamika Sharma

anysharma70@gmail.com

Irum Alvi

irumalvi@gmail.com

1 Faculty of Management, MBA Programme, Rajasthan Technical University, Kota, Rajasthan, India

2 HEAS Dept., Rajasthan Technical University, Kota, India 


\section{Introduction}

The lockdown due to COVID 19 seems to have generally caused a severe impact on the learning of higher education students as they were in the middle of their even semesters and this lockdown imposed on them, led to a shift in their learning methods. These students were not able to learn on a one on one basis with their educators, as the pandemic initiated an immediate and complete closedown of all the educational institutions, the shift in learning from traditional classroom learning to computer-based learning became one of the greatest academic changes which the students needed to cope with. The current study has been undertaken to comprehend the student's perception about the imposed changes in learning methods due to COVID 19 problem at higher education institutions. Thus, it helps in developing better understanding of required educational reforms in the pandemic and post pandemic times, as education system need to be transformed significantly instead of waiting for normalcy.

\section{Background of the study}

The post COVID-19 world demanded each establishment to remodel digitally. This digitalization is taking place in India, but the overall speed of change has increased dramatically after the pandemic (Gupta, 2020). In the present times, due to the exceptional situation of COVID-19, the education pedagogy and mode of teaching learning methodologies are to be changed overnight (Gupta, 2020). The conventional system i. e. a combination of online and offline leaning methods, is to be altered to a new system of teaching and learning that could support students with providing an appropriate online learning experience (Roy, 2020). There are numerous online platforms providing different programs with distinctive methodology, evaluation outcomes and certificates but what is needed is an integrated learning system (Augustine, 2020). Students registering in online learning courses have been rising dramatically and this overall multiplying demand for online learning has been accelerated by various reasons which included cost effectiveness, the flexibility of time and place, opportunity to attend classes digitally, space for performing different wide and varied works of day to day lives of adults, a reduced amount of distraction in comparison to face-to-face learning (Hannay \& Tracy, 2018; Kirtman, 2009; Nguyen, 2015; Xu \& Jaggars, 2013). Despite of rise in the numbers of online learners, the online learning has always been connected with several risks like lack of teachers' presence, lack of interaction with peers in comparison to face-to face learning, poor motivation, unsuccessful management of time schedules, and lack of individual learning abilities (Cole et al., 2004; Golladay et al., 2000; Hannay \& Tracy, 2018; Kirtman, 2009; McKeachie, 2002; Nguyen, 2015; Ryan, 2001; Serwatka, 2003; Xu \& Jaggars, 2013). In PostCOVID times educators and learners are forced to adopt web-assisted learning. 
Web-assisted ways of e-learning use internet, websites, telecommunication, radio, video recording etc. for performing different activities like delivering lectures, providing study materials, assignments (Masrom, 2007; Young et al., 2008). It is much like face-to-face learning in which classroom teaching and live interactions between teachers and students take place, when both of them are online at a certain time to communicate directly with each other (Kalpana, 2010; Buzzetto-More, 2015). Several studies have been undertaken for exploring and comparing students' perceptions regarding e-learning and traditional learning in term of social presence, social interaction, and satisfaction, found that e-learning is perceived as lacking in social interaction, social presence, and effective synchronized communication, it provides several benefits including convenience and ease of time, an easy understanding of critical concepts and subjects and gives opportunities to work while learning (Cuthrell \& Lyon, 2007; Bali and Liu, 2018; Smart \& Cappel, 2006). On the other side, studies like the research by Tratnik (2017) discovered that students enrolled in traditional courses of study had been in general more satisfied with a few select factors than the online learners. Kemp and Grieve (2014) found that undergraduate students desired to accomplish activities face-to-face more than on the internet, though the levels of academic performance are similar in both the methods. According to other studies, classroom dynamics and social activities which are essential parts of face-to-face regular learning encourage learning engagement that results in successful, productive and meaningful learning with better results (Carini et al., 2006; Hurst et al., 2013). Furthermore, researches show that students' perception of online learning in higher education tend to be greatly influenced by factors like age, gender, learners' computer knowledge and technology tolerance, patterns of learning, lack of awareness, interest, personal touch, and interaction due to connectivity issues (Arora \& Srinivasan, 2020; Keller \& Cernerud, 2002). Another study discovered that most of the learners prefer learning through online classes, but they feel that these classes are deficient in of co-curricular activities (Lall \& Singh, 2020). Since, face-to-face learning opportunities are affected by the pandemic; educational institutions took an alternative and complementary path of web-assisted online classes, providing learning opportunities for students (Jain \& Ruby, 2020; Nandakumar, 2020). In the present study, the researchers explore the impact of this inevitable transformation, from face-to-face learning to learning with the support of technology which enabled uninterrupted and structured online learning in this uncertain scenario of the countrywide lockdown.

\subsection{Statement of the problem}

In the present pandemic environment the main focus of teaching and learning has been on maintaining consistency in delivering quality education. Unfortunately pandemic situation with imposed lockdown has forced educational institutions to adopt online learning methods, but the previous studies established that students are not in favour of using technology like mobile phones to assess online education (Papadakis 
et al., 2017) which are essential to deal with this crisis. Therefore, the effectiveness of these new ideas of remote learning need to be evaluated, to have a clear understanding of effectiveness of these methods. The present empirical study tries to evaluate learners' perception of these leaning methods, so that teachers can adopt suitably and provide consistent and quality education. Developing a better comprehension of learners' perception of web-assisted learning methods could help in better implementation of these methods and provide consistency in these times of crisis.

\subsection{Objectives}

The key aims of the study are:

- To examine the affect of COVID 19 on learning methods.

- To identify the different aspects significant for learning.

- To find the differences in the perception of learning methods of the same students in Pre and Post COVID 19 Pandemic.

\subsection{Hypothesis}

To fulfill the research objective, the following hypothesis was framed:

H0: There is no statistically significant difference in the students' perception towards Pre-Pandemic and Post-Pandemic learning methods.

Research design selected for the study was an exploratory research design to identify the students' perception towards select aspects of in Pre and Post Pandemic Education. The design is also descriptive as it not only evaluates the learners' perception in a higher education institution of India but also compares the difference the perception of the same students in Pre and Post COVID 19 period, using SPSS 23.0 and JASP 0.14.1 software applications.

This quantitative study used a same sample pre-test, post-test design to assess students' perceptions. Selection and Size of the Sample Sample size may significantly affect all outcomes in any quantitative exploration. The impacts of sample size are seen most legitimately in the statistical significance of testing and the generalizability of the outcomes. Sample size is likewise a significant consideration for the internal consistency of items utilized in the scales. Given these contemplations, a sample size of 366 for was viewed as satisfactory for the present study, considering the average size of samples utilized by different researchers in comparative and similar investigations. Convenience sampling technique was utilized to for selecting the sample. The method was considered as suitable as the purpose of the investigation was to scrutinize the students' points of view and to explore differences, if any, in their perception of the Pre and Post-Pandemic Learning. The sample consisted of 290 male $(79.2 \%)$, and $76(20.8 \%)$, the average age was approximately 20 years. Research Instrument Information was 
gathered utilizing an online survey based on earlier investigations. Minor modifications were made to improve simplicity of comprehension in light of the fact that the survey was in English. The research instrument comprised of two segments, Demographic segment and segment relating to different aspects of pre and post learning. Demographic data included several items about sex, age, branch, domicile etc. The modified survey comprised of 20 items prompting replies to a five-point Likert scale, stretching from firmly disagree to firmly agree. All items were adopted and altered from earlier studies. Additionally, a control factor of the investigation was the way that the students had studied for half of the II/Even semester prior to the lockdown and the second half of the same semester after lockdown due to the pandemic. Because of limitations of time only few aspects of learning were chosen, Flexibility, Personalization, Sufficiency and Accessibility, Usability, Content Quality, Providing guidance Services, Instructor's attitude, Instructor's responsiveness, Instructor's enthusiasm, Instructor's interactive Communication. Flexibility is considered an essential aspect in measuring the effectiveness of learning (Sedera et al., 2004; Selim, 2003). The flexibility of learning structures may be determined by measuring how readily usable is the learning content and information, for the learner. While Personalization has been established by previous researches refers to the personalized learning experience in learning enhances which significantly influences its effectiveness (Delone \& McLean, 2003; Ozkan \& Koseler, 2009). The characteristics such as personalized sharing of information, individual discussions and queries handling etc. are determinants which assist in measuring the personalization. Sufficiency and Accessibility role is evident from earlier studies; sufficiency and accessibility are crucial determinants of learning effectiveness (Delone \& McLean, 2003; Ozkan $\&$ Koseler, 2009; Selim, 2003). In learning, sufficiency and accessibility of the information provided to a learner contribute immensely and turn out to be overall deciding factor of an effective learning management system. Usability of learning structures is another key aspect of learning (Ozkan \& Koseler, 2009; Sedera et al., 2004). It helps in reaching the goals of learning and increases the frequency of learning efforts of any learner. Content quality is a key and crucial aspect in measuring the effectiveness of learning. The effectiveness of information and e-learning structures depends on the information quality which assists in achieving learning goals and the poor quality of information resulted in several serious problems. (Al-sabawy, 2013). It is also determined by how effectively the content is presented and organized in terms of its length, accuracy, lucidity, relevance and usefulness (Shee \& Wang, 2008). Providing guidance Services is also essential. In the several studies on online learning system, guidance Services such as ethics and policies which define regulations, restrictions, rules as well as directions for communicating within the system, data confidentiality, and other such subject matters are found significant to its success therefore influence the learners immensely. (Chang \& King, 2005; Khan, 2005; Hassanzadeh et al., 2012). The role of Instructor's attitude has been affirmed by several previous studies. An instructor's attitude is an important aspect in determining the quality of managing education system (Hiltz, 1993; Islas et al., 2009; Khan, 2005; Selim, 2007; Webster \& Hackley, 1997). Webster and Hackley (1997) state those instructors' 
Table 1 Different aspects of learning methods and the related studies

\begin{tabular}{lll}
\hline S.No & Aspects & $\begin{array}{l}\text { Related Studies } \\
\text { Item modified and adapted from Studies }\end{array}$ \\
\hline 1 & Flexibility & Sedera et al. (2004); Selim (2003) \\
2 & Personalization & Ozkan and Koseler (2009); Delone and McLean (2003) \\
3 & Sufficiency and Accessibility & Delone and McLean (2003); Ozkan and Koseler (2009); \\
& & Selim (2003) \\
4 & Usability & Sedera et al. (2004); Ozkan and Koseler (2009) \\
5 & Content Quality & Ozkan and Koseler (2009) \\
6 & Providing guidance Services & Chang and King (2005), Hassanzadeh et al. (2012) \\
7 & Instructor's attitude & Lee et al. (2009), Sun et al. (2008) \\
8 & Instructor's enthusiasm & Sun et al. (2008) \\
9 & Instructor's responsiveness & Ozkan and Koseler (2009), Sun et al. (2008) \\
10 & Instructor's interactive & Sun et al. (2008); Ozkan and Koseler (2009) \\
& Communication & \\
\hline
\end{tabular}

attitudes towards a technology, their teaching styles, and their command over the technology influences the learning results. Equally important is the instructor's enthusiasm. It is a significant determinant for learning effectiveness (Sun et al., 2008). In learning, the quality of instructor is overall deciding factor of an effective learning management system. In the similar way, Gilbert highlights the significance the 'instructor' and reveals the fact that it's not the general technology itself but the instructional practice of the technology that decides its effects on learning (Gilbert, 2007). Instructor's prompt responses to queries and issues from instructors have high impact on the effectiveness of learning (Ozkan \& Koseler, 2009; Sun et al., 2008). Instructor's interactive Communication is also important. Liaw purported that 'instructor' will be the significant aspect in reference to online learning. In learning perspectives, instructors need to have sufficient time to have interaction with the learners during the learning process (Khan, 2005; Liaw, 2002). Table 1 gives these aspects and the related studies from which the instrument items were adapted after required modification.

\section{Research framework}

This research tries to shed light on the learners' perception of web-assisted learning methods in comparison to blended learning methods implemented in the educational institution in the pre-COVID times. The research evaluates select aspect of learning, including Flexibility, Usability, Sufficiency and Accessibility, Content Quality, Guidance Services, Personalization, Instructors' responsiveness, Instructors' interactive, Instructors' attitude, Instructors' enthusiasm in relation to pre and post COVID learning methods i.e. Blended learning vs. Web-assisted learning. Figure 1 shows the framework for the study: 


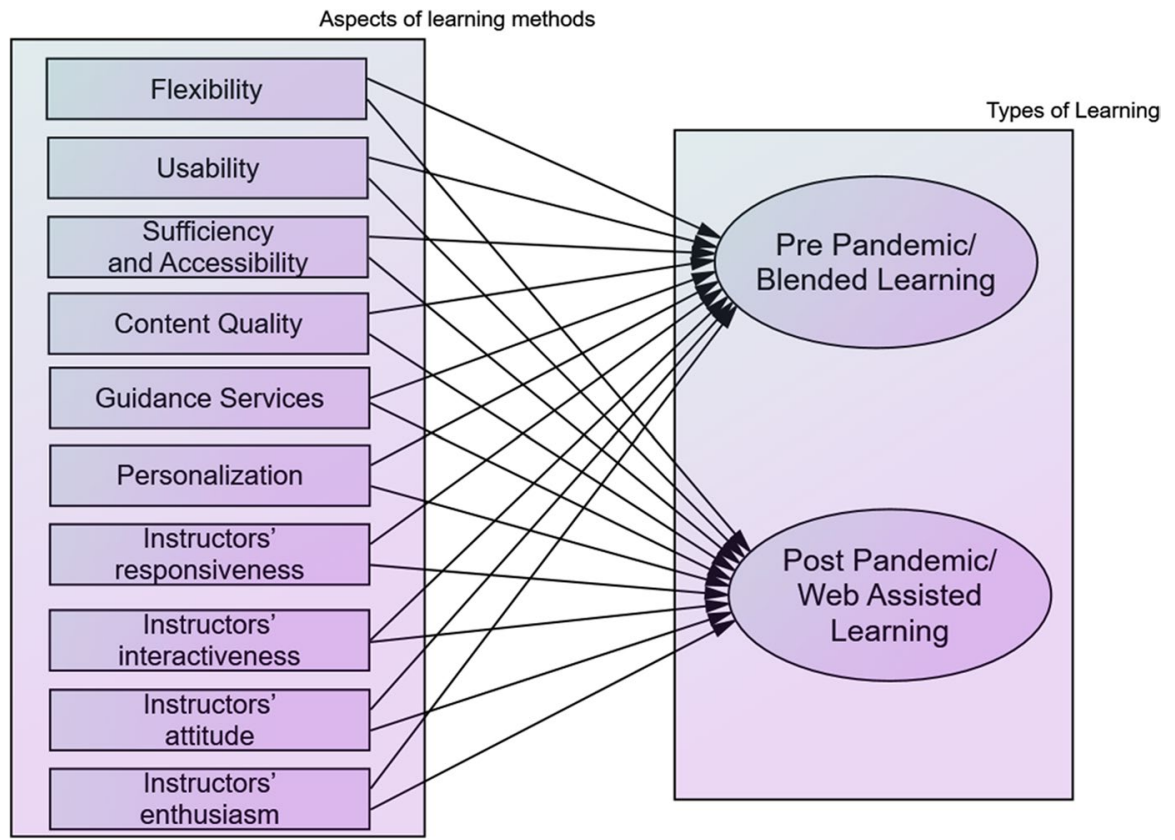

Fig. 1 Conceptual framework

\section{Results and analysis}

\subsection{Demographic details of the respondent}

The study population included students studying in the First Year of a technical institute. It was also required that participants were capable of reading English and using a computer. It was also ensured that the participants had been exposed to both pre and post pandemic learning due to the lockdown in the mid semester. For the present study, data was gathered from 366 I Year, II Semester, students from a University in Rajasthan, using an online questionnaire, during the present session i.e. 2019-20, wherein the students studied for half of the session in the college and half of the session at home due to lockdown because of Pandemic. The sample consists of 290 male (79.2\%), and $76(20.8 \%)$. The average age of the respondents was 20.2 years.

\subsection{Statistical analysis}

The data gathered from the online questionnaire was moved to an Excel spreadsheet that was encoded and moved to the Statistical Package for Social Sciences program (SPSS) version 23.0 and JASP 0.14.1 software applications for exploration. A total of 366 responses were found suitable from the 400 responses received. The data was inspected for outliers. Furthermore exploratory factor analysis was carried out. Descriptive statistics (means, medians, and standard deviations) were considered for 
defining the populace and identifying trends between variables. A t-test was conducted to compare students' perception of Pre and Post Pandemic learning methods.

\section{Results}

Kaiser-Meyer-Olkin- KMO sampling adequacy test and Bartlett's Sphericity tests were used so as to confirm that the data gathered is appropriate and satisfactory for Exploratory Factor analysis. Table 1 shows the results of the Tests. While the Bartlett's test surveys overall implication of correlation matrix, the KMO measures the factorability of the variables as independent and as a group which are essential presumptions of factor analysis. Based on the results of Bartlett's Test shown in Table 2 it may be well deduced that the correlations amongst the variables selected for the investigation, together are significant at $1 \%$ level. This show there is non-zero correlations between them. However, the measure of sampling sufficiency considers not only the correlations, but also the correlation patterns which exist between the variable. The value observed for general sampling adequacy was 0.939 which is in the accepted range i.e. 0.50. As the tests satisfied essential and elementary suppositions for exploratory factor analysis, the data was regarded as reasonable fit for exploratory factor analysis.

A Principal Component Exploration was utilized to discover factors which expound maximum variance in the data. The Eigen values were measured as the criteria for selecting the quantity of factors to be recognized alongside cumulative percentage of variance explicated. Just the factors with Eigen value over 1 are extracted. This measure resulted in only two factors from the twenty items. Varimax rotation was utilized to produce the component matrix, as it guarantees that the variables stay uncorrelated all through the procedure of rotation. The factor loadings indicate to the degree to which a variable is related with a factor as depicted in Table 3. When the factors are inspected for their loadings, all values were observed to be above the estimation of 0.5. Along these lines none of the variables are excluded in the study. Based on the Exploratory Factor Analysis results, the resultant two factors were termed as Pre-Pandemic Learning/Blended Learning and Post-Pandemic learning/Web Assisted Learning. The two factors derived are found to be explaining a total of $66.135 \%$ of the variances in the data considered for the study.

For testing internal consistency in data collected, Cronbach's alpha values were determined. Tavakol and Dennick (2011) propose Cronbach's alpha is a significant idea for assessment of evaluations and surveys and the scholars must gauge this measure to enhance legitimacy and precision

Table 2 KMO and bartlett's test

\begin{tabular}{lll}
\hline Kaiser-Meyer-Olkin Measure of Sampling Adequacy & 0.939 \\
\hline Bartlett's Test of Sphericity & Approx. Chi-Square & 5420.632 \\
& Df & 190 \\
& Sig & 0.000 \\
\hline
\end{tabular}




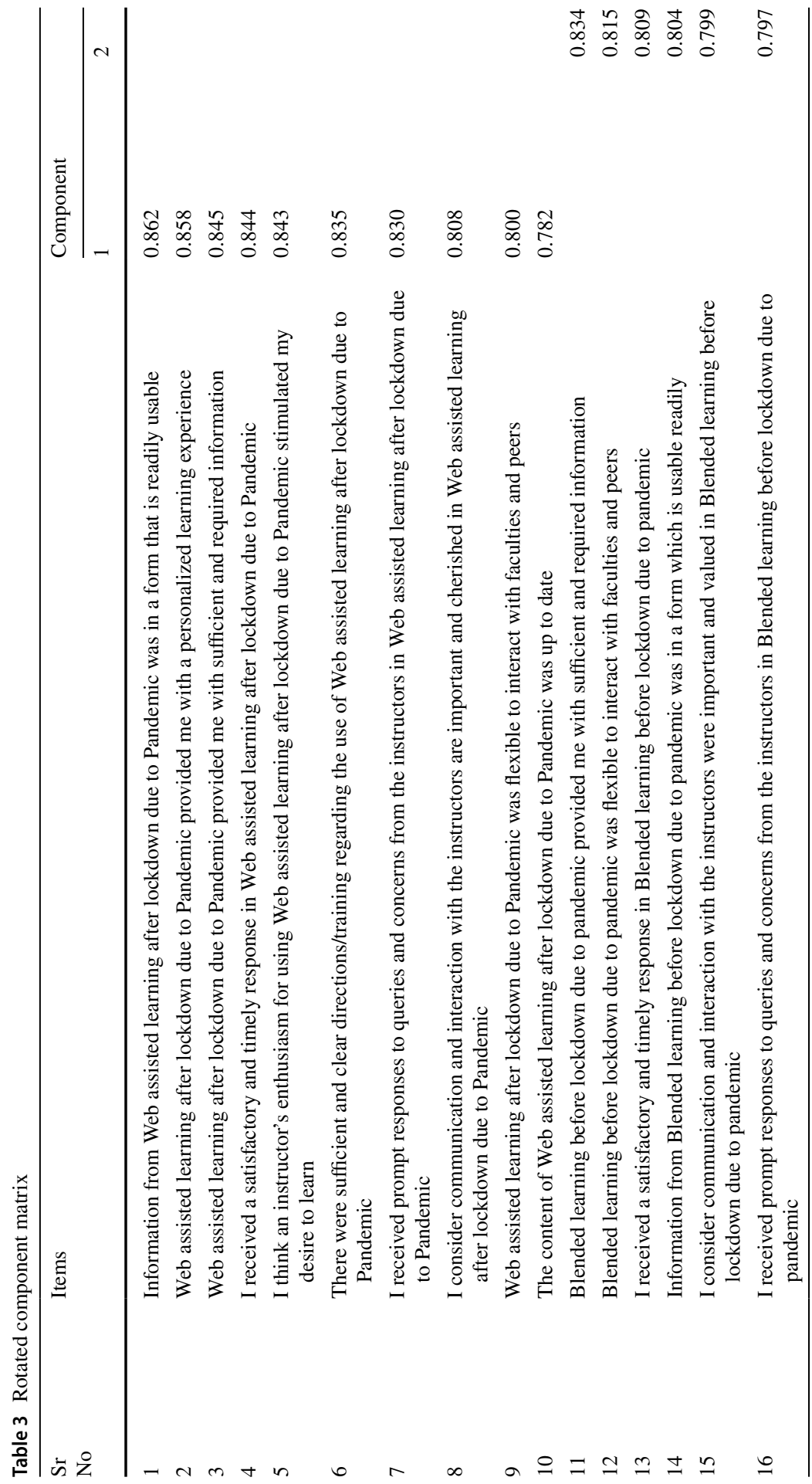




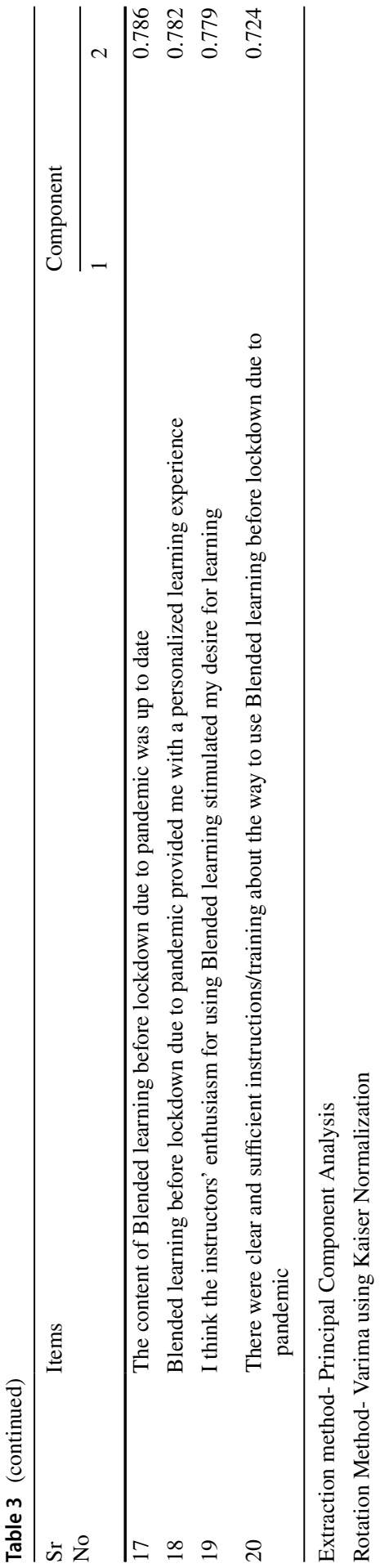


Table 4 Cronbach's alpha reliability statistics

\begin{tabular}{lll}
\hline Pre-Pandemic Learning & Post-Pandemic Learning & No of Items \\
\hline 0.934 & 0.950 & 10 \\
\hline
\end{tabular}

to the data elucidation. The reliability of the data as checked by computing Cronbach- $\alpha$ values for the two factors identified using exploratory factor analysis. The Table 4 exhibits the values 0.934 and 0.950 for Pre and Post Pandemic learning, which were considered appropriate. The number of items for each was ten.

The test of normality, Shapiro-Wilk test was rum to check if the data was normally distributed (Table 5). It was found that the data is not normally distributed as the test was significant for all the aspects of learning being considered for the present study.

As the data for all aspects of learning was not normally distributed and the supposition for normality is violated, therefore, Wilcoxon's signed rank test, which is the equivalent non-parametric test, was conducted for options: Wilcoxon signed rank, location parameter and effect size. The Table 6 below shows the descriptive statistics.

The output table generated using JASP is displayed in Table 7 for paired sample $t$ test conducted. The paired $t$ test results for select aspect of learning, $\mathrm{F}=$ Flexibility, $\mathrm{U}=$ Usability, $\mathrm{SA}=$ Sufficiency and Accessibility, $\mathrm{CQ}=\mathrm{Con}-$ tent Quality, $\mathrm{GS}=$ Guidance Services, $\mathrm{P}=$ Personalization, $\mathrm{IR}=$ Instructors' responsiveness, II = Instructors' interactive, IA = Instructors' attitude, $\mathrm{IE}=$ Instructors' enthusiasm and overall learning based on summation of the various aspects were significantly reduced $p<001$ for all aspects except personalization, which is significant at 0.03 . The Hodges- Lehmann values, location parameter, which is the median difference between the two groups ranged from 0.500 to 1.500 for the select factors. The rank-bi serial correlation (rB)

Table 5 Test of normality (Shapiro-Wilk)

\begin{tabular}{llll}
\hline Pre Pandemic & Post Pandemic & W & $\mathrm{p}$ \\
\hline Flexibility & - Flexibility & 0.958 & $<0.001$ \\
Usability & - Usability & 0.957 & $<0.001$ \\
Sufficiency and Accessibility & - Sufficiency and Accessibility & 0.955 & $<0.001$ \\
Content Quality & - Content Quality & 0.957 & $<0.001$ \\
Guidance Services & - Guidance Services & 0.958 & $<0.001$ \\
Personalization & - Personalization & 0.870 & $<0.001$ \\
Instructors' responsiveness & - Instructors' responsiveness & 0.947 & $<0.001$ \\
Instructors' interactive & - Instructors' interactive & 0.956 & $<0.001$ \\
Instructors' attitude & - Instructors' attitude & 0.963 & $<0.001$ \\
Instructors' enthusiasm & - Instructors' enthusiasm & 0.944 & $<0.001$ \\
Total & - Total & 0.984 & $<0.001$ \\
\hline
\end{tabular}

Significant results suggested a deviation from normality 
Table 6 Descriptive statistics for pre and post pandemic learning

\begin{tabular}{llllllllllll}
\hline & & F & U & SA & CQ & GS & P & IR & II & IA & IE \\
\hline Post Pandemic & Valid & 339 & 339 & 339 & 339 & 339 & 339 & 339 & 339 & 339 & 339 \\
Mdn=31 & Median & 3 & 3 & 3 & 3 & 3 & 4 & 3 & 3 & 3 & 3 \\
& Min & 1 & 1 & 1 & 1 & 1 & 1 & 1 & 1 & 1 & 1 \\
& Max & 5 & 5 & 5 & 5 & 5 & 5 & 5 & 5 & 5 & 5 \\
Pre Pandemic & Valid & 339 & 339 & 339 & 339 & 339 & 339 & 339 & 339 & 339 & 339 \\
Mdn=40 & Median & 4 & 4 & 4 & 4 & 4 & 4 & 4 & 4 & 4 & 4 \\
& Min & 1 & 1 & 1 & 1 & 1 & 1 & 1 & 1 & 1 & 1 \\
& Max & 5 & 5 & 5 & 5 & 5 & 5 & 5 & 5 & 5 & 5 \\
\hline
\end{tabular}

$F$ Flexibility, $U$ Usability, $S A$ Sufficiency and accessibility, $C Q$ Content quality, GS Guidance services, $P$ Personalization, IR Instructors' responsiveness, II Instructors' interactive, IA Instructors' attitude, IE Instructors' enthusiasm

was considered as effect size and was construed the same as Pearson's r, for all aspects of learning under consideration, the effect size was small to large, as the Rank-bi serial (rB) are inferred as $<0.1$ trivial, 0.1 trivial, 0.3 moderate and 0.5 large.

The effect size ranged from small for Personalization $=0.257$, Content Quality $=0.269$, to Medium for Instructors' attitude $=0.471$, and large for Usability $=0.55$, Instructors' interactive $=0.588$, Flexibility $=0.64$, Guidance Services $=0.653$, Instructors' responsiveness 0.666 Instructors' enthusiasm $=0.671$, and Sufficiency $=0.721$. The CI that is the Confidence Intervals were also calculated as shown in Table 7.

The paired t-tests were conducted to compare about students' perception of Pre and Post Pandemic Learning. A noteworthy significant difference was observed in the students' Pre-Pandemic Learning scores $(\mathrm{Mdn}=40)$ compared to Post-Pandemic score $(\mathrm{Mdn}=31)$; $\mathrm{W}=41,813.500, \mathrm{p}<0.000$.The Wilcoxon $\mathrm{W}$-statistic was extremely significant as $\mathrm{p}<0.001$. The location parameter called the Hodges-Lehmann estimate indicated the median difference among the groups, with effect size of 0.628 which is a large effect size. Thus, hypothesis H0, which states 'There will be no statistically significant difference in the students' perception towards in Pre-Pandemic and Post-Pandemic learning' was rejected, as significant differences were found, which showed students' perceptions about Pre-pandemic learning was more favorable in comparison with Post-pandemic.

\section{Discussion}

The study analyzed and confirmed that there was a significant affect of pandemic on learning methods as well as students' perceptions towards the learning methods used. The prevalent methods of classroom learning and blended e-learning 


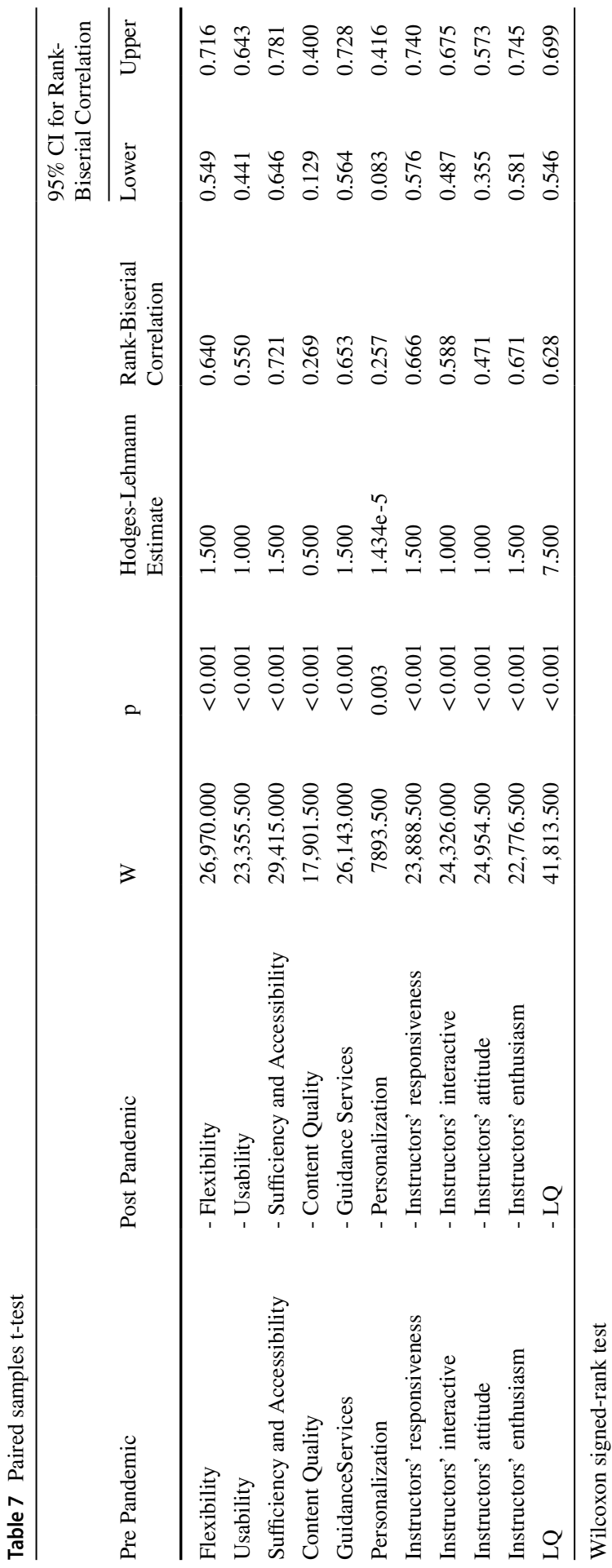


methods were replaced by web-assisted method of e-learning because of the lockdown to contain the COVID 19 pandemic. The present study scrutinized the students' perspectives towards the pre and post Pandemic leaning with special emphasis on the various aspects of learning methods used including Flexibility, Personalization, Sufficiency and Accessibility, Usability, Content Quality, Providing guidance Services, Instructor's attitude, enthusiasm, responsiveness and interactive communication.

For the main research question formulated for the present study, it was established that there exists a statistically significant dissimilarity in the students' perceptions of the Pre and Post Pandemic learning. The students had significantly higher perception of the Pre-Pandemic learning which indicated that they had more affirmative opinions about blended e-learning; they did not have the same perception towards post pandemic learning which demonstrated that they had more affirmative impression of blended learning; however, they didn't have a similar perception towards Post Pandemic learning which was web-assisted or web based learning alone.

A possible explanation is that it was the first time that they had experienced it which led to significant differences in their perception towards the post pandemic learning scenario. It may be noted that the current semester was of six months; therefore the students spent three months learning prior to the lockdown and three months after the lockdown due to the pandemic. It is possible that the students didn't have enough time to get used to the new and novel methods being adopted by the teachers, so there was no significant difference in their perception between their responses before and after the pandemic. The effect of the pandemic on the students should be surveyed in the long run, thereby providing the students enough time to get used to the new methods of learning.

The findings confirmed that blended e-learning methods are perceived better than the web assisted e-learning methods by the students. The results of the present study confirm the findings and add to extant literature by endorsing Tagoe's findings (2012), which revealed that students preferred the mixed mode of courses to e-learning courses. The present study revealed that the students perceived blended e-learning as a more attractive proposition than the web assisted learning. The results differ from prior studies (e.g. Singh \& Thurman, 2019), which found the students preferred being independent, for learning from instructors or other students. The cause may be their low preparedness with regards to using online Systems (Parkes et al., 2014) or the lack of internet facilities/ resources. Therefore the main focus of the instructors should not be merely on adoption of Web-based learning in the course of crises, such as the COVID 19 Pandemic, but be on the development and improvement of the quality of learning during the emergency (Affouneh et al., 2020).

\subsection{Limitations of the study}

Though respondents of the present study were learners from varied colleges of different regions, and branches, cultures, enrolled in one university in 
Rajasthan, India, the legitimacy and dependability of the inferences will accelerate in case different higher educational institutions of the State were scrutinized. The further studies may extend the general exploration to institutions of higher education in other States of the country. Additionally, the study was based on the respondents' perceptions of some select aspects of learning. Various other aspects may also be included in future studies. Diverse groups of e-learning contributors, including lecturers and administrators, could contribute to upgrade the research with their distinctive opinions and provide a higher appreciation of the problems facing teaching and learning methods during the post-pandemic times. Moreover, the study has its own limitations, the sample consists of engineering students from only one University in Rajasthan, and so the conclusions obtained cannot be generalized to other students.

\subsection{Recommendations for further study}

Further research can widen the diversity of the analyzed groups and give more insight into the matter, using larger and more varied samples from other technical colleges and universities. Furthermore, the methodology used few statistical tools, which may be supplemented with other more suitable methodologies, for studying the influence of the pandemic on the students' learning. Future work may also provide useful insight into the mediating effects of other variables such as gender, age, family background, cultural background, etc. on the students' perception of learning. In a nutshell, further and on-going research is essential to discover the immediate and longitudinal impact of the pandemic on the students, using newer, larger and more varied samples.

It is recommended that for enhancing post pandemic learning system, academics should put additional efforts like giving discussion time or practice sessions where students could involve into peer communication as well as give extra time to increase effective communications with learners (using Online/Google classrooms/ Internet etc.). They should try to motivate and to promote learners to discuss topics with their peers, as well as to engage students in discussions for improving peer collaborations (Hiltz \& Goldman, 2005).

\subsection{Implications}

(a) Theoretical Implications - The novelty of the work is in the use of original data to find out the students' perception of Pre and Post-Pandemic learning and gauge the differences, which adds to the existing literature in the field of Learning. The present research confirms that there exist differences in the students' perception of the pre and post pandemic learning.

(b) Practical Implication -The practical implication of this investigation is that it may help empower policymakers, educators and administrators of universities and colleges by revealing the students' perceptions of learning. 


\section{References}

Affouneh, S., Salha, S. N., \& Khlaif, Z. (2020). Designing quality e-learning environments for emergency remote teaching in coronavirus crisis. Interdisciplinary Journal of Virtual Learning in Medical Sciences, 11(2), 1-3.

AL-Sabawy, A. Y. (2013). Measuring e-learning systems success. Doctoral dissertation, University of Southern Queensland.

Arora, A. K., \& Srinivasan, R. (2020). Impact of pandemic COVID-19 on the teaching-learning process: a study of higher education teachers. Prabandhan: Indian Journal of Management, 13(4), 43-56. https://doi.org/10.17010/pijom/2020/v13i4/151825.

Augustine, M. G. (2020). COVID-19 and learning history. Indian academy of sciences. http://confl uence.ias.ac.in/covid-19-and-learning-history/. Accessed 18 Aug 2020.

Bali, S. \& Liu, M C (2018). Students' perceptions toward online learning and face-to-face learning courses. Journal of Physics: Conf. Series, 1108. https://doi.org/10.1088/1742-6596/1108/1/ 012094. Accessed 19 July 2020.

Buzzetto-More, N. (2015). Student attitudes towards the integration of youtube in online, hybrid, and web-assisted courses: An examination of the impact of course modality on perception. MERLOT Journal of Online Learning and Teaching, 11(1). http://jolt.merlot.org/vol11no1/BuzzettoMore_ 0315.pdf. Accessed 25 July 2020.

Carini, R., Kuh, G., \& Klein, S. (2006). Student engagement and student learning: Testing the linkages. Research in Higher Education, 1, 1-32.

Chang, J. C. J., \& King, W. R. (2005). Measuring the performance of information systems: A functional scorecard. Journal of Management Information Systems, 22(1), 85-115.

Cole, M. S., Field, H. S., \& Harris, S. G. (2004). Student learning motivation and psychological hardiness: Interactive effects on students' reactions to a management class. Academy of Management Learning \& Education, 3(1), 64-85.

Cuthrell, K., \& Lyon, A. (2007). Instructional strategies: What do online students prefer? MERLOT Journal of Online Learning and Teaching, 3(4), 357-362.

Delone, W. H., \& Mclean, E. R. (2003). The Delone and Mclean model of information system success: A ten-year update. Journal of Management Information System, 19(4), 9-30.

Gilbert, J. (2007). E-learning: the student experience. British Journal of Educational Technology, 4(38), 560-573.

Golladay, R., Prybutok, V., \& Huff, R. (2000). Critical success factors for the online learner. Journal of Computer Information Systems, 40(4), 69-71.

Gupta V. (2020). Re-imagining engineering education in a post Covid-19 world. https://bloncampus. thehindubusinessline.com/b-learn/re-imagining-engineering-education-in-a-post-covid-19world/ article32003296.ece. Accessed 10 Aug 2020.

Hannay, M., \& Tracy, N. (2018). Perceptions of distance learning: A comparison of online and traditional learning. Journal of Online Learning and Teaching, 2(1), 1-11.

Hassanzadeh, A., Kanaani, F., \& Elahi, S. (2012). A model for measuring e-learning systems success in universities. Expert Systems with Applications, 39, 10959-10966.

Hiltz, R. S. (1993). The virtual classroom: learning without limits via computer networks. Ablex Corporation Publishing.

Hiltz, S. R., \& Goldman, R. (2005). Learning together online: Research on asynchronous learning networks. Lawrence Erlbaum Associates.

Hurst, B., Wallace, R., \& Nixon, S. (2013). The impact of social interaction on student learning. Reading Horizons, 52(4), 375-398.

Islas, E., et al. (2009). E-learning tools evaluation and roadmap development for an electrical utility. Journal of Theoretical and Applied Electronic Commerce Research (JTAER), 1(2), 63-75.

Jain, E., \& Ruby, A. (2020). Can India achieve its enrolment target post-pandemic? www.university worldnews.com/post.php?story=20200725092411819. Accessed 10 Aug 2020.

Kalpana, V. (2010). Future trends in e-learning. IEEE 2010 4th International Conference on Distance Learning and Education (ICDLE). Accessed 11 Aug 2020.

Keller, C., \& Cernerud, L. (2002). Students' perception of e-learning in university education. Learning, Media and Technology, 27, 55-67.

Kemp, N., \& Grieve, R. (2014). Face-to-face or face-to-screen? Undergraduates' opinions and test performance in classroom vs. online learning. Educational Psychology, 5, 1-14. 
Khan, B. K. (2005). E-learning quick check list. i.s.: Information Science Publishing.

Kirtman, L. (2009). Online versus in-class courses: An examination of differences in learning outcomes. Issues in Teacher Education, 18(2), 103-117.

Lall, S., \& Singh, N. (2020). CoVid-19: Unmasking the new face of education. International Journal of Research in Pharmaceutical Sciences, 11(SPL1), 48-53. https://doi.org/10.26452/ijrps.v11iSPL1. 2122.

Lee, B.-C., Yoon, J.-O., \& Lee, I. (2009). Learners' acceptance of e-learning in South Korea: Theories and results. Computer and Education, 53, 1320-1329.

Liaw, S. S. (2002). An Internet survey for perceptions of computer and world wide web: relationship, prediction, and difference. Computers in Human Behavior, 1(18), 17-35.

Masrom, M. (2007). Technology acceptance model and e-learning. In: 12th International Conference on Education, 21-24 May 2007, Sultan Hassanal Bolkiah Institute of Education, Universiti Brunei Darussalam http://eprints.utm.my/5482/1/MaslinMasrom2006_Techn.pdf. Accessed 11 Aug 2020.

McKeachie, W. (2002). McKeachie's teaching tips: Strategies, research, and theory for college and university teachers. (11th ed.). Houghton Mifflin.

Nandakumar, P. (2020). Startups redefine online medical education during COVID crisis. https://www. theweek.in/news/india/2020/06/27/startups-redefine-online-medical-education-during-covidcrisis. html. Accessed 10 Aug 2020.

Nguyen, T. (2015). The effectiveness of online learning: Beyond no significant difference and future horizons. MERLOT Journal of Online Learning and Teaching, 11(2), 309-329.

Ozkan, S., \& Koseler, R. (2009). Multi-dimensional students' evaluation of e-learning systems in the higher education context: An empirical investigation. Computers \& Education, 53(4), 1285-1296.

Papadakis, S., Kalogiannakis, M., Sifaki, E., \& Vidakis, N. (2017). Access moodle using smart mobile phones. A case study in a Greek University. In Interactivity, game creation, design, learning, and innovation (pp. 376-385). Springer.

Parkes, M., Stein, S., \& Reading, C. (2014). Student preparedness for university e-learning environments. The Internet and Higher Education, 25, 1-10. https://doi.org/10.1016/j.iheduc.2014.10.002.

Roy S. (2020). Covid-19: Prestigious universities moving online, but can digital learning compensate for campus experience? https://www.financialexpress.com/education-2/covid-19-prestigious-universiti es-moving-online-butcan-digital-learning-compensate-for-campus-experience/2020964/. Accessed 15 July 2020.

Ryan, S. (2001). Is online learning right for you? American Agent \& Broker, 73(6), 54-58.

Selim, H. M. (2003). An empirical investigation of student acceptance of course websites. Computers and Education, 40(4), 343-360.

Selim, H. M. (2007). Critical success factors for e-learning acceptance: Confirmatory factor models. International Journal of Technology Marketing, 2(2), 157-182.

Serwatka, J. (2003). Assessment in on-line CIS courses. Journal of Computer Information Systems, 43(3), 16-20.

Sedera, D., Gable, G., \& Chan, T. (2004). A factor and structural equation analysis of the enterprise systems success measurement model. Association for Information Systems. In L. Appelgate, R. Galliers, \& J. I. Degross (Eds.), Proceedings of the twenty-fifth international conference on information systems. Association for Information Systems.

Shee, D. Y., \& Wang, Y. S. (2008). Multi-criteria evaluation of the web-based e-learning system: A methodology based on learner satisfaction and its applications. Computers \& Education, 3(50), 894-905.

Singh, V., \& Thurman, A. (2019). How many ways can we define online learning? A systematic literature review of definitions of online learning (1988-2018). American Journal of Distance Education, 33(4), 289-306.

Smart, K. L., \& Cappel, J. J. (2006). Students' perceptions of online learning: A comparative study. Journal of Information Technology Education, 5. http://jite.org/documents/Vol5/v5p201-219Smart54. pdf. Accessed 19 July 2020.

Sun, P., Tsai, R., Finger, G., Chen, Y., \& Yeh, D. (2008). What drives a successful e-Learning? An empirical investigation of the critical factors influencing learner satisfaction. Computers \& Education, 50(4), 1183-1202.

Tavakol, M., \& Dennick, R. (2011). Making sense of Cronbach's alpha. International Journal of Medical Education, 2, 53-55.

Tagoe, M. (2012). Students' perceptions on incorporating e-learning into teaching and learning at the University of Ghana. International Journal of Education and Development using Information and Communication Technology (IJEDICT), 8(1), 91-103. 
Tratnik, A. (2017). Student satisfaction with an online and a face-to-face Business English course in a higher education context. Journal Innovations in Education and Teaching International, 15(1), $1-10$.

Webster, J., \& Hackley, P. (1997). Teaching effectiveness in technology-mediated distance learning. Academy of Management Journal, 40(6), 1282-1309. https://doi.org/10.2307/257034.

Xu, D., \& Jaggars, S. (2013). Examining the effectiveness of online learning within a community college system: An instrumental variable approach. CCRC Working Paper No. 56. Columbia: CCRC Reseach Center.

Young, B. Hausler, J. \& Sanders, J. (2008). Do online students exhibit different learning styles than onsite students? International Journal of Instructional Technology and Distance Education, 5(4). http:// www.itdl.org/Journal/Apr_08/article02.htm. Accessed 18 Aug 2020.

Publisher's note Springer Nature remains neutral with regard to jurisdictional claims in published maps and institutional affiliations. 